\title{
$\begin{array}{llllllll}F & O & R & E & W & O & R & D\end{array}$
}

\section{The old and the modern}

\author{
A. Béry, D. Brézulier, S. Carolus
}

If a man keeps cherishing his old knowledge, so as continually to be acquiring new, he may be a teacher of others.

The elder can become a master. Confucius

To celebrate the 50 years of the DFO Journal, the Editorial Committee decided to delve into the archives to share a wealth of often forgotten information.

The choices were not easy. That is why we have chosen only a few themes, illustrating our treatment philosophies and our daily practice. To do this we have a put a previously published text (the old) alongside what could be described as an updated version (the modern).

This issue, which is in fact very special and focuses on interviews, will enable you to read, or re-read, facsimiles of articles and to understand the evolution of orthodontic concepts over the course of the past half-century. Evolution is not always where you think.

After a reminder on the "why and how" of the review, we will delve into fiction. Then, back to reality, we will look at the philosophies of Ricketts and Tweed, treatment of classes II and III, canines included, orthognathic surgery, the choice of thread and the contribution of functional rehabilitation.

We hope that this issue will satisfy you and that we can continue to count you among our diligent readers for both this issue and those to follow in the next 50 years!

Alain Béry, Damien Brézulier and Sophie Carolus

Editors

\section{The editors of this journal hope}

you have an excellent 2017! 